University of Nebraska - Lincoln

DigitalCommons@University of Nebraska - Lincoln

Faculty Publications: Department of Entomology

2009

\title{
Oxalic acid: A prospective tool for reducing Varroa mite populations in package bees
}

Nicholas P. Aliano

University of Nebraska-Lincoln, naliano@unlserve.unl.edu

Marion D. Ellis

University of Nebraska-Lincoln, mellis3@unl.edu

Follow this and additional works at: https://digitalcommons.unl.edu/entomologyfacpub

Part of the Entomology Commons

Aliano, Nicholas P. and Ellis, Marion D., "Oxalic acid: A prospective tool for reducing Varroa mite populations in package bees" (2009). Faculty Publications: Department of Entomology. 181. https://digitalcommons.unl.edu/entomologyfacpub/181

This Article is brought to you for free and open access by the Entomology, Department of at DigitalCommons@University of Nebraska - Lincoln. It has been accepted for inclusion in Faculty Publications: Department of Entomology by an authorized administrator of DigitalCommons@University of Nebraska - Lincoln. 
Published in Experimental and Applied Acarology 48 (2009), pp. 303-309;

doi: 10.1007/s10493-009-9240-8 Copyright (๑) 2009 Springer Science+Business Media B.V.

Used by permission.

Submitted October 1, 2008; accepted January 9, 2009; published online January 31, 2009.

\title{
Oxalic acid: \\ A prospective tool for reducing Varroa mite populations in package bees
}

\author{
Nicholas P. Aliano and Marion D. Ellis \\ University of Nebraska-Lincoln \\ Corresponding author - N. P. Aliano, University of Nebraska-Lincoln, \\ 1320 Q Street, Lincoln, NE 68588-0467, USA; email nickaliano@gmail.com
}

\begin{abstract}
Numerous studies have investigated using oxalic acid (OA) to control Varroa mites in honey bee colonies. In contrast, techniques for treating package bees with $\mathrm{OA}$ have not been investigated. The goal of this study was to develop a protocol for using OA to reduce mite infestation in package bees. We made 97 mini packages of Varroa-infested adult bees. Each package contained 1,613 \pm 18 bees and $92 \pm 3$ mites, and represented an experimental unit. We prepared a $2.8 \%$ solution of OA by mixing $35 \mathrm{~g}$ OA with 11 of sugar water (sugar: water $=1: 1 ; w: w)$. Eight treatments were assigned to the packages based on previous laboratory bioassays that characterized the acute contact toxicity of OA to mites and bees. We administered the treatments by spraying the OA solution directly on the bees through the mesh screen cage using a pressurized air brush and quantified mite and bee mortality over a 10-day period. Our results support applying an optimum volume of $3.0 \mathrm{ml}$ of a $2.8 \% \mathrm{OA}$ solution per 1,000 bees to packages for effective mite control with minimal adult bee mortality. The outcome of our research provides beekeepers and package bee shippers guidance for using OA to reduce mite populations in package bees.
\end{abstract}

Keywords: Varroa destructor, Apis mellifera, oxalic acid, package, bioassay

\section{Introduction}

Numerous studies have investigated using oxalic acid (OA) to control Varroa mites in honey bee colonies. In contrast, techniques for treating package bees with OA have not been investigated. A review of literature regarding the efficacy of OA (Rademacher and Harz 2006) indicates that broodless colonies are ideal for OA application. Oxalic acid does not kill mites in sealed brood cells (Schuster and Schürzinger 2003), and it is less effective when brood is present (Fuchs 1990; Gregorc and Planinc 2001). 
Oxalic acid is most effective in broodless colonies because Varroa mites are phoretic on adult bees, and mites inevitably come in physical contact with OA when it is applied.

Treating package bees with OA is a logical extension of the usefulness of OA as a Varroa mite control agent because all mites present in packages are phoretic on adult bees. A recent article by Strange et al. (2008) indicates that Varroa infestation levels vary widely in packages from US producers, ranging from 0.4 to 5.4 mites per 100 bees. The goal of this study was to develop a protocol for using OA to reduce mite infestation in package bees. This study establishes an optimum volume of a $2.8 \% \mathrm{OA}$ solution for spraying on package bees to provide effective mite control while minimizing adult bee mortality.

\section{Materials and methods}

Stocking of packages

We shook $25 \mathrm{~kg}$ of Varroa-infested adult honey bees from 20 source colonies into a bulk bee box on the evening of May 25th, 2006. The source colonies were located at the University of Nebraska-Lincoln's Agricultural Research and Development Center (ARDC) near Mead, NE. We had previously caged the queens from the source colonies to ensure that all mites were phoretic on adult bees (May 5). The source colonies were two or three stories high and were composed of a mixture of Italian and Carniolan bees. We added one frame of honey, two frames of pollen and nectar, one frame of unsealed brood, and one frame with 15 caged queens to stabilize the bulk bee box. In addition, we fit the bulk bee box with top feeders that contained 61 of light syrup and 31 of water. We maintained the bulk box overnight to allow the bees to cluster and the mite population to become equally distributed.

The next day, we made 97 packages of adult bees by subdividing the adult bee population in the bulk bee box (May 6). The packages were $10.2 \mathrm{~cm}$ long, $8.3 \mathrm{~cm}$ wide, and $17.8 \mathrm{~cm}$ high. We provided each package with a 0.51 scoop of adult bees. Each package contained 1,613 \pm 18 bees and $92 \pm 3$ mites. We moved the packages to a dark, air-conditioned laboratory where we fit each package with a 0.51 top feeder containing light syrup (sugar:water $=1: 1 ; \mathrm{w}: \mathrm{w}$ ). We placed three large fans in the laboratory to remove $\mathrm{CO}_{2}$ and to prevent the packages from overheating. The daily temperature and relative humidity inside the laboratory averaged $23 \pm 2^{\circ} \mathrm{C}(n=6)$ and $63.6 \pm 9 \%$ $(n=6)$, respectively.

Determination of the OA concentration and volumes to apply to the packages

The Canadian Honey Council has provided the American Beekeeping Federation their registration data packet to expedite the registration of OA in the USA. As a result, the recommended concentration of the OA solution that will appear on the US label will most likely be identical to the Canadian label. Therefore, we chose to test one concentration of OA based on the Canadian treatment recommendations for honey bee colonies. The Canadian label recommends dissolving $35 \mathrm{~g}$ of OA dihydrate in 11 of warm syrup made from a mixture of sugar and water (sugar:water =1:1; weight:volume; Special Supplement 2005). This mixture results in a $2.8 \%$ OA sugar water solution by weight (sugar:water $=1: 1 ; \mathrm{w}: \mathrm{w}$ ).

We used bioassay data from Aliano et al. (2006) to determine the maximum volume of OA to apply to the packages. Aliano et al. (2006) estimated the $48 \mathrm{~h} \mathrm{LD}_{50}$ for 
adult honey bees to be $372 \mu \mathrm{g}$ per bee (95\% CL $=307-440 \mu \mathrm{g}$ per bee). We picked a high volume of $15 \mathrm{ml}$ of a $2.8 \%$ OA solution per package to approximate a dose that was slightly less than the $48 \mathrm{~h} \mathrm{LD}{ }_{50}$ for adult honey bees (equivalent to $9.3 \mathrm{ml}$ per 1,000 bees). A volume greater than $15 \mathrm{ml}$ may have resulted in the premature death of packages so we decided to err on the side of caution. Our calculations were as follows: $35 \mathrm{~g}$ of $\mathrm{OA}$ in 11 of sugar water results in $\sim 0.035 \mathrm{~g} \mathrm{OA} / \mathrm{ml}$ solution. Fifteen milliliter of OA solution $\times 0.035 \mathrm{~g} \mathrm{OA} / \mathrm{ml}$ solution $=0.525 \mathrm{~g}$ OA per package. A package contains 1,618 bees, hence $325 \mu \mathrm{g}$ OA per bee.

We chose eight volumes of OA to apply to the packages: $0,1,3,5,7,9,11$, and $15 \mathrm{ml}$ of a $2.8 \%$ OA solution per package, equivalent to $0.0,0.6,1.8,3.1,4.6,5.4,6.7$, and $9.3 \mathrm{ml}$ of a $2.8 \% \mathrm{OA}$ solution per 1,000 bees, respectively.

Treatment and data collection

We randomly assigned the 97 packages to the eight treatment groups defined above. We prepared a $2.8 \%$ solution of OA by mixing $35 \mathrm{~g}$ OA with 11 of sugar water (sugar: water $=1: 1 ; \mathrm{w}: \mathrm{w})$. We administered the treatments by spraying the OA solution directly on the bees through the mesh screen cage using a pressurized air brush (King Spark Hardware \& Tool Corporation, model AB-105, Taichung County, Taiwan). We pipetted the appropriate volume of OA solution into the air brush gravity cup (paint cup) for each treatment and sprayed the adult bee cluster until the solution was gone. We made an effort to maximize OA contact with the adult bees by spraying both sides of the screen cages.

We placed sticky boards in the packages prior to OA application to monitor mite fall. We replaced the sticky boards 3, 6, and 10 days post-treatment to estimate 3, 6, and 10 day Varroa mite mortality. In addition, we recovered dead bees 3,6 , and 10 days post-treatment by removing them from the packages (Figure 1). We chilled the packages at $2^{\circ} \mathrm{C}$ for $20 \mathrm{~min}$ to force the bees to cluster and facilitate dead bee recovery $(3,6$, and 10 days post-treatment). The packages had a sliding screened side that allowed us to remove dead bees from the bottom of the packages while leaving the cluster of live bees undisturbed. After counting the number of dead bees at each time interval, we washed the bees in alcohol to recover the mites that had fallen into the pile of dead bees instead of landing on the sticky boards below. We added the number of mites collected on the sticky boards to the number of mites collected from the dead bees to estimate the Varroa mite mortality for each time interval.

At the end of the experiment, we killed and counted the remaining bees in the packages by spraying them with $70 \%$ alcohol. In addition, we recovered the remaining mites using the alcohol wash method (Shimanuki and Knox 2000). We were able to calculate the total number of bees and mites present in each package prior to OA application by destructively sampling the packages at the end of the experiment. Specifically, we added the number of mites collected from sticky boards and dead bees 3 , 6 , and 10 days post-treatment to the number of mites collected from live bees at the end of the experiment to calculate the total number of mites present in each package prior to experimentation. Similarly, we added the number of dead bees collected 3, 6, and 10 days post-treatment to the number of live bees remaining at the end of the experiment to calculate the total number of bees present in each package prior to experimentation. This enabled us to calculate the proportion of mites and bees killed in each package 3, 6, and 10 days post-treatment. The 97 packages contained a total of 9,309 mites and 162,934 bees. 

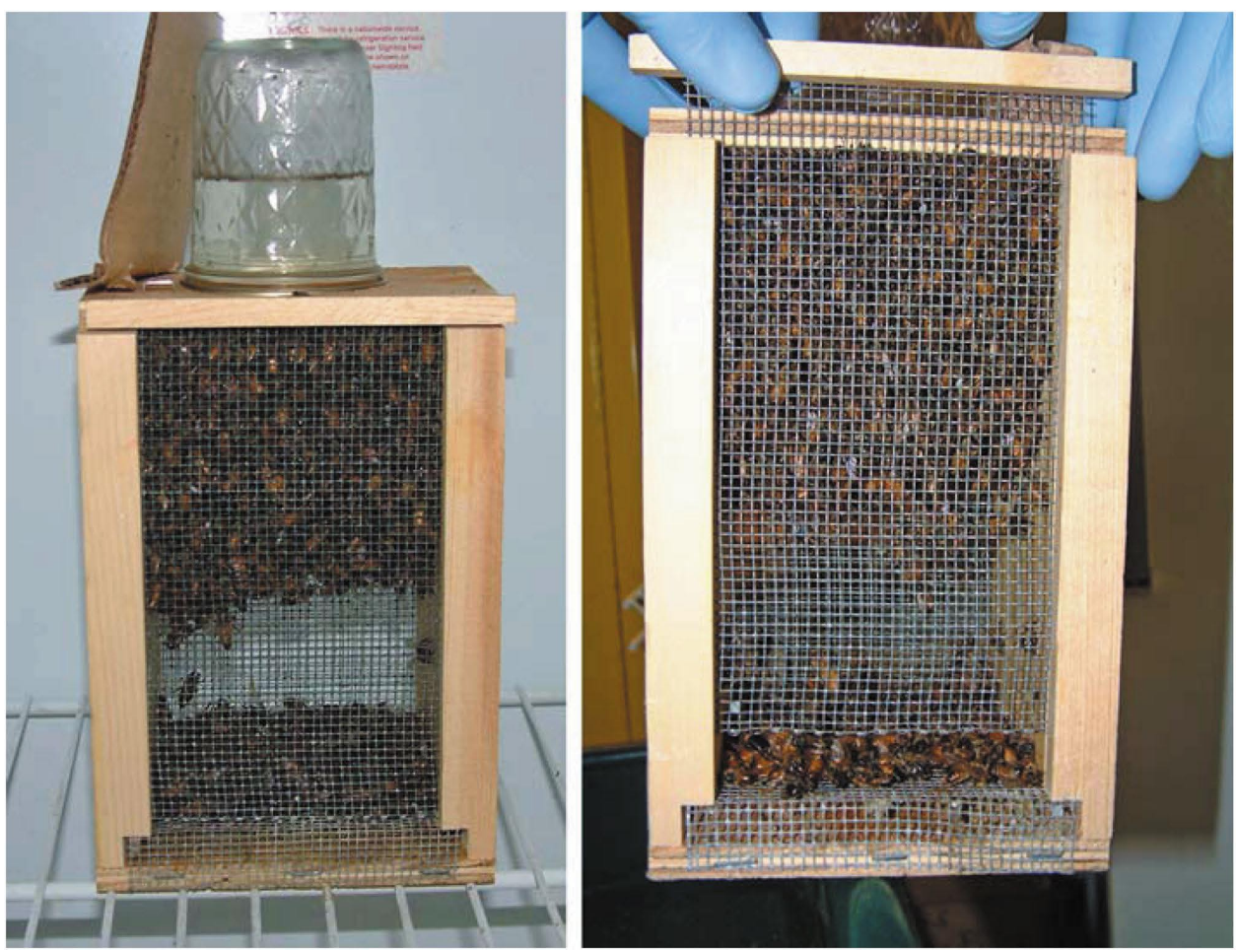

Figure 1. Left: The packages were chilled at $2^{\circ} \mathrm{C}$ for $20 \mathrm{~min}$ to force the bees to cluster. Right: Front view of the package highlighting the sliding screened side used to collect dead adult bees.

Experimental design and statistical analysis

Our experiment followed a completely randomized design (CRD). We used the proportion of mites and bees killed 3, 6, and 10 days post-treatment as response variables. We used PROC GLIMMIX to analyze both the mite and bee proportion data and used a binomial response distribution (SAS Institute 2006). We fit a generalized linear model (GLM) with a binomial response distribution implemented in PROC GLIMMIX. We separated means using a $t$-test $(a=0.05)$. In addition to the PROC GLIMMIX analysis, we fit the same model using the NLMIXED procedure (SAS Institute 2006) to calculate the lethal doses (LD's) for both mites and bees 3, 6, and 10 days post-treatment.

\section{Results}

\section{Lethal doses of OA for mites and bees}

We found that the 10-day $\mathrm{LD}_{50}$ for honey bees was $6.16 \mathrm{ml}$ per 1,000 bees, well above the 10-day $\mathrm{LD}_{50}$ for mites $(1.14 \mathrm{ml}$ per 1,000 bees; Table 1$)$. Note that the $\mathrm{LD}_{50}$ is listed 3,6 , and 10 days post-treatment. In addition, the table lists the $\mathrm{LD}_{90}$ and $\mathrm{LD}_{95}$ for mites and the $\mathrm{LD}_{10}$ and $\mathrm{LD}_{15}$ for honey bees because our objective was to choose a dose that provided effective mite control while minimizing adult bee mortality. 
Table 1. Honey bee and Varroa mite mortality responses to a 2.8\% OA solution at 3-10 days after spraying on package bees.

\begin{tabular}{|c|c|c|c|c|c|c|c|}
\hline \multicolumn{2}{|c|}{ Mortality (days) } & \multirow{2}{*}{$\frac{n}{162,934}$} & \multirow[t]{2}{*}{$\mathrm{LD}_{95}$} & \multirow[t]{2}{*}{$\mathrm{LD}_{90}$} & \multirow{2}{*}{$\begin{array}{l}\mathrm{LD}_{50} \\
7.97 \\
(7.93-8.01)\end{array}$} & \multirow{2}{*}{$\begin{array}{l}\mathrm{LD}_{15} \\
3.80 \\
(3.77-3.84)\end{array}$} & \multirow{2}{*}{$\begin{array}{l}\mathrm{LD}_{10} \\
2.60 \\
(2.56-2.64)\end{array}$} \\
\hline 3 & Bees & & & & & & \\
\hline & Mites & 9,309 & $\begin{array}{l}3.83 \\
(3.74-3.91)\end{array}$ & $\begin{array}{l}3.25 \\
(3.18-3.33)\end{array}$ & $\begin{array}{l}1.57 \\
(1.51-1.62)\end{array}$ & & \\
\hline \multirow[t]{2}{*}{6} & Bees & 162,934 & & & $\begin{array}{l}7.45 \\
(7.41-7.48)\end{array}$ & $\begin{array}{l}3.28 \\
(3.24-3.31)\end{array}$ & $\begin{array}{l}2.08 \\
(2.04-2.12)\end{array}$ \\
\hline & Mites & 9,309 & $\begin{array}{l}3.55 \\
(3.47-3.64)\end{array}$ & $\begin{array}{l}2.98 \\
(2.91-3.05)\end{array}$ & $\begin{array}{l}1.29 \\
(1.23-1.35)\end{array}$ & & \\
\hline \multirow[t]{2}{*}{10} & Bees & 162,934 & & & $\begin{array}{l}6.16 \\
(6.13-6.19)\end{array}$ & $\begin{array}{l}2.00 \\
(1.96-2.03)\end{array}$ & $\begin{array}{l}0.79 \\
(0.75-0.84)\end{array}$ \\
\hline & Mites & 9,309 & $\begin{array}{l}3.41 \\
(3.32-3.49)\end{array}$ & $\begin{array}{l}2.83 \\
(2.76-2.90)\end{array}$ & $\begin{array}{l}1.14 \\
(1.08-1.20)\end{array}$ & & \\
\hline
\end{tabular}

Lethal doses ( $\mathrm{ml}$ per 1,000 bees) are followed by $95 \%$ confidence limits in brackets.

Proportion of mites killed as response variable

We modeled the factors time, volume, and the time $\times$ volume interaction. The time $\times$ volume interaction was not significant $\left(F_{14,267}=0.06, P=1.0\right)$. The time effect was also not significant $\left(F_{2,267}=0.27, P=0.77\right)$, indicating that mite mortality 3 days post-treatment was not significantly different from mite mortality 6 or 10 days posttreatment. The volume effect was significant $\left(F_{7,267}=10.09, P=0.0001\right)$. Table 2 lists the main effect estimates of the proportion of mites killed for each of the eight volumes. Volumes $\geq 3.1 \mathrm{ml}$ of a $2.8 \%$ OA solution per 1,000 bees resulted in $\geq 94 \%$ mite mortality. In addition, increasing the volume above $3.1 \mathrm{ml}$ per 1,000 bees did not significantly increase mite mortality. Figure 2 illustrates the Varroa mite mortality response to a $2.8 \%$ OA solution when sprayed on package bees. The standard error bars were intentionally not included because they overlap for each time interval and clutter the graph. The standard error for each volume is listed in Table 2.

Table 2. Estimates $( \pm \mathrm{SE})$ of the proportion of Varroa mites and honey bees killed when package bees were sprayed with a $2.8 \%$ OA solution at various volumes $(0-9.3 \mathrm{ml}$ per 1,000 bees).

\begin{tabular}{llll}
\hline Volume & Varroa mites & Honey bees & $n$ \\
\hline 0.0 & $0.07 \pm 0.04 \mathrm{a}$ & $0.05 \pm 0.04 \mathrm{a}$ & 36 \\
0.6 & $0.22 \pm 0.07 \mathrm{~b}$ & $0.07 \pm 0.04 \mathrm{a}$ & 36 \\
1.8 & $0.76 \pm 0.07 \mathrm{c}$ & $0.10 \pm 0.05 \mathrm{ab}$ & 36 \\
3.1 & $0.94 \pm 0.04 \mathrm{~d}$ & $0.15 \pm 0.05 \mathrm{ab}$ & 42 \\
4.6 & $0.97 \pm 0.03 \mathrm{~d}$ & $0.22 \pm 0.07 \mathrm{bc}$ & 36 \\
5.4 & $0.99 \pm 0.02 \mathrm{~d}$ & $0.21 \pm 0.07 \mathrm{bc}$ & 36 \\
6.7 & $0.98 \pm 0.03 \mathrm{~d}$ & $0.35 \pm 0.09 \mathrm{c}$ & 30 \\
9.3 & $0.99 \pm 0.02 \mathrm{~d}$ & $0.79 \pm 0.06 \mathrm{~d}$ & 39 \\
\hline
\end{tabular}

$\overline{\text { Estimates with different letters within a column indicate significant differences }(t \text {-test, }}$ $a=0.05)$. 


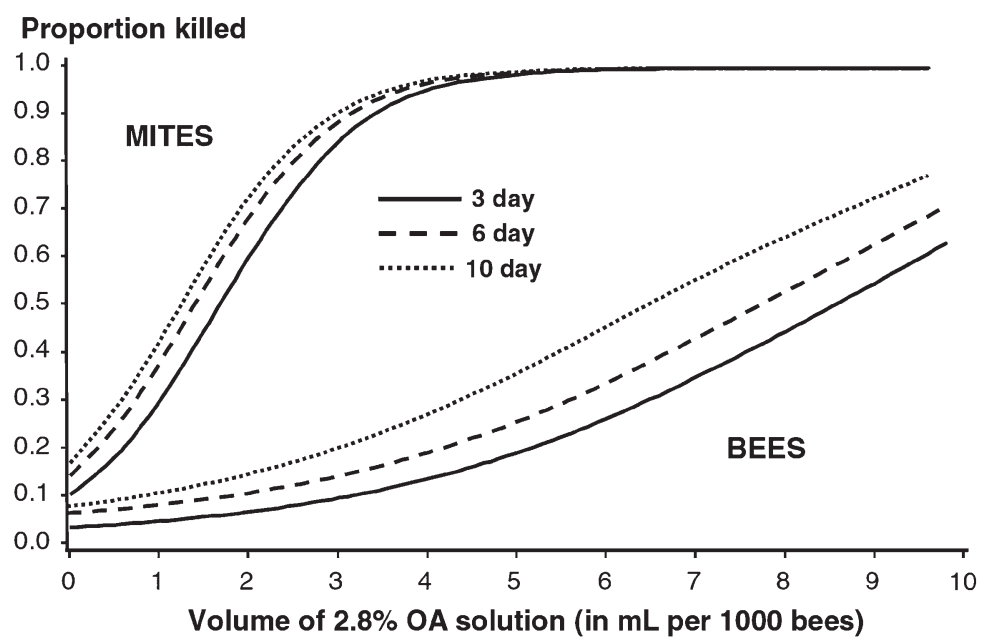

Figure 2. Varroa mite and honey bee mortality response to a $2.8 \%$ OA solution when sprayed on package bees.

Proportion of bees killed as response variable

The time $\times$ volume interaction was not significant $\left(F_{14,267}=0.05, P=1.0\right)$. Also the time effect was not significant $\left(F_{2,267}=2.61, P=0.076\right)$, indicating that bee mortality 3 days post-treatment was not significantly different from bee mortality 6 or 10 days post-treatment. The volume effect was significant $\left(F_{7.267}=7.67, P=0.0001\right)$. In general, volumes $\geq 4.6 \mathrm{ml}$ of a $2.8 \%$ OA solution per 1,000 bees caused significant adult bee mortality when compared to untreated packages (Table 2). Figure 2 illustrates the adult bee mortality response to a $2.8 \%$ OA solution when sprayed on package bees. The standard error for each volume is listed in Table 2.

\section{Discussion}

Our data indicate an optimum volume providing effective mite control while minimizing adult bee mortality when sprayed on package bees: $3.0 \mathrm{ml}$ of a $2.8 \%$ OA sugar water solution (sugar:water $=1: 1 ; \mathrm{w}: \mathrm{w}$ ) per 1,000 bees to packages resulted in $>90 \%$ mite control and no significant bee mortality. This volume was based on the 6-day Varroa mite $\mathrm{LD}_{90}$ because the 3- and 10-day time intervals are not realistic. For example, bees must remain in their package for at least 3 days before they become a swarm (personal observation). In general, beekeepers do not install packages 3 days after they were created because of additional shipping transit time. The 10-day time interval is also unrealistic because significant bee mortality occurs if packages are left caged for 10 days. Therefore, the intermediate 6-day time interval is the most realistic. In addition, Table 2 indicates that there was no significant difference between the proportions of mites killed on package bees when volumes $\geq 3.1 \mathrm{ml}$ per 1,000 bees were applied (0.94-0.99). Also, volumes $\geq 4.6 \mathrm{ml}$ per 1,000 bees caused significant adult bee mortality when compared to untreated packages. The $3.1 \mathrm{ml}$ per 1,000 bee volume resulted in $10 \%$ greater bee mortality than untreated packages, but this difference was not statistically significant (Table 2). Thus, $3.0 \mathrm{ml}$ per 1,000 bees is the ideal volume to apply to packages. 
The easiest method for preparing a $2.8 \%$ solution of OA is to mix $35 \mathrm{~g}$ OA dihydrate with 11 of warm sugar water (Special Supplement 2005). Although a pressurized air brush was used to apply small volumes of the OA solution in this study, beekeepers may use a non-pressurized spray bottle. Another option for OA application is a MeterJet ${ }^{\mathrm{TM}}$ Spray Gun Kit. The MeterJet ${ }^{\mathrm{TM}}$ Spray Gun can be attached to a Solo ${ }^{\circledR}, \mathrm{D}$. B. Smith ${ }^{\circledR}$, or SP Systems ${ }^{\mathrm{TM}}$ sprayer and delivers a precise metered volume of solution with each pull of the trigger.

Our data for treating package bees with OA is useful because it provides beekeepers and package bee shippers a starting point for using OA to reduce mite populations from package bees or bulk bee boxes. Our data indicate that small deviations in the amount of OA applied to packages result in drastically different outcomes. For example, although the $3.1 \mathrm{ml}$ per 1,000 bees volume did not cause significant bee mortality, the $4.6 \mathrm{ml}$ per 1,000 bees volume did. Therefore, the applicator should emphasize accurate measurements when mixing and applying OA to package bees.

The optimum dosage of OA described herein is not a recommendation, but rather, a starting point for future researchers. We have not demonstrated that the application of $3.0 \mathrm{ml}$ of a $2.8 \%$ OA sugar water solution (sugar:water $=1: 1 ; \mathrm{w}: \mathrm{w}$ ) per 1,000 bees is an efficacious, safe Varroa treatment method for packages in a replicated field study. The implications of our results are limited to small packages $(1,613 \pm 18$ bees) that do not contain queens. Scientists and beekeepers that desire to use OA to treat packages should test our protocol on a few packages to verify that significant adult bee mortality does not occur. Additionally, abiotic factors like temperature and humidity may affect adult bee mortality and vary by regional climate.

\section{References}

Aliano NP, Ellis MD, Siegfried BD (2006) Acute contact toxicity of oxalic acid to Varroa destructor (Acari: Varroidae) and their Apis mellifera (Hymenoptera: Apidae) hosts in laboratory bioassays. J Econ Entomol 99(5):1579-1582

Fuchs S (1990) Preference for drone brood cells by Varroa jacobsoni Oud. in colonies of Apis mellifera carnica. Apidologie (Celle) 21(3):193-199. doi: 10.1051/apido:19900304

Gregorc A, Planinc I (2001) Acaricidal effect of oxalic acid in honeybee (Apis mellifera) colonies. Apidologie (Celle) 32:333-340. doi: 10.1051/apido:2001133

Rademacher E, Harz M (2006) Oxalic acid for the control of varroosis in honey bee colonies - a review. Apidologie (Celle) 37:98-120. doi: 10.1051/apido:2005063

SAS Institute (2006) SAS/STAT user's guide, version 9.1. SAS Institute, Cary

Schuster H, Schürzinger F (2003) Oxalsäure zur Sommerbehandlung? Allg Dtsch Imkerztg $1: 27-28$

Shimanuki H, Knox DA (2000) Diagnosis of honey bee diseases. US Department of Agriculture, Agricultural handbook No. AH-690, 61p

Special supplement (2005) Conditions of use for: oxalic acid dihydrate for control of varroa mites in honey bee colonies. Hivelights 18(4). www.honeycouncil.ca/documents/LableOxalicE.pdf

Strange JP, Cicciarelli RP, Calderone NW (2008) What's in that Package? An evaluation of quality of package honey bee Apis mellifera L. (Hymenoptera: Apidae) shipments in the US. J Econ Entomol 101(3):668-673. doi: 10.1603/0022-0493(2008)101[668: WITPAE]2.0.CO;2 